\title{
The Application of Acceptance Commitment Therapy (ACT) and Family Psychoeducation (FPE) to Clients with Schizophrenia and Aggressive Behavior
}

\author{
Andi Buanasari ${ }^{1}$, Budi Anna Keliat ${ }^{2}$, Herni Susanti $^{2}$ \\ ${ }^{l}$ Nursing Department, Faculty of Medicine, Sam Ratulangi University, Indonesia \\ ${ }^{2}$ Faculty of Nursing, Universitas Indonesia, Indonesia \\ Corresponding Author: Budi Anna Keliat (budianna_keliat@yahoo.com)
}

\begin{abstract}
Background: Aggressive behavior frequently occurs in clients with schizophrenia and causes injuries to the clients themselves, others, and the environment. It becomes one of the most common factors causing rehospitalization in schizophrenic clients. Aggressive behavior can be managed by the intervention administered by nurses in the usual way (treatment as usual; TAU) as well as psychotherapy (acceptance and commitment therapy; ACT and family psychoeducation; FPE).

Purpose: This study aimed to investigate the effectiveness of acceptance and commitment therapy (ACT) and family psychoeducation (FPE) on schizophrenic clients with aggressive behavior.

Methods: This study used a case series method to report four selected cases of schizophrenic clients with aggressive behavior. Acceptance and commitment therapy (ACT), family psychoeducation (FPE), and treatment as usual (TAU) were delivered to four clients with aggressive behavior for six weeks using the Stuart Stress-Adaptation Model.

Results: The finding showed decreased symptoms of aggressive behavior in cognitive, affective, physiological, behavioral, and social aspects and increased ability to control anger, to accept their problems, and to commit to the therapy after ACT, FPE, and TAU interventions.

Conclusion: This report showed that TAU, ACT, and FPE effectively decreased the symptoms of aggressive behavior and increased the clients' ability to control anger.

Keywords: Acceptance and commitment therapy; family psychoeducation; aggressive behavior; case series; schizophrenia

How to cite: Buanasari, A., Keliat, B. A., \& Susanti, H. The application of acceptance commitment therapy (ACT) and family psychoeducation (FPE) to clients with schizophrenia and aggressive behavior. Nurse Media Journal of Nursing, 10(1), 11-21. doi:10.14710/nmjn.v10i1.22220
\end{abstract}

Permalink/DOI: https://doi.org/10.14710/nmjn.v10i1.22220 


\section{BACKGROUND}

Aggressive behavior is one of the responses to stressors that appears as self-destruction and causes damage to others and the environment either verbally or non-verbally. Aggressive behavior is exhibited mostly by clients with schizophrenia (Stuart, 2013). According to previous research, 3,187 clients with schizophrenia experienced the risk of violent behavior such as attacking and threatening 4.3 times higher than the general population (Fleischman, Werbeloff, Yoffe, Davidson, \& Weiser, 2014). Another study showed that of 1,033 patients with schizophrenia, 31\% (1 in 3 patients) were aggressive and hostile (Knezevic et al., 2016).

Aggressive behavior in schizophrenia is associated with the lack of 5hydroxyindoleacetic acid (5-HIAA) concentration and the enhancement of dopamine and norepinephrine metabolism in cerebrospinal fluid which causes an impulsive response (Stanley et al., 2000). Command hallucinations such as listening to the voice of command to harm and to commit suicide are also the trigger factors of aggressive behavior in clients with schizophrenia (Haddock, Eisner, Davies, Coupe, \& Barrowclough, 2013), while other factors include a history of childhood aggressive behavior, antisocial personality disorder, substance abuse, and unpleasant experiences (Volavka \& Citrome, 2011). Unpleasant experiences that cause feelings of insecurity, rejection, and tenderness tend to be expressed by someone with aggressive behavior to cover up those feelings (Stuart, 2013).

The aggressive behavior committed by clients with schizophrenia might increase the cost of health care because it is the most frequent cause of clients' admission to the hospital, and the length of stay will be longer since the signs of aggressive behavior are persistent (Volavka, 2014). Another impact of aggressive behavior is the enhancement of stigma in society because people with mental disorders are considered to be dangerous and should be avoided, leading to discrimination and social inequality (Torrey, 2011). This stigma becomes the strongest reason for the family to undertake confinement or locking (pasung) of clients with schizophrenia and aggressive behavior (Buanasari, Daulima, \& Wardani, 2017).

There are three stages of aggressive behavior management in clients with schizophrenia which are prevention strategies through education and assertive training; anticipatory strategies such as proper communication and environmental modification, including family, medication, and psychotherapy; and crisis management through seclusion and restrain (Stuart, 2013). The effectiveness of prevention strategies through social way and de-escalation has been revealed in the previous studies to be able to improve the clients' ability to control anger and to reduce the intensity of seclusion and restrain as well as invasive interventions (Richmond et al., 2012; Keliat, Azwar, Bachtiar, \& Hamid, 2009).

Anticipatory strategies through usual nursing intervention which combines physical, social, spiritual, and medication methods significantly reduce the length of stay in the hospital (Keliat, Azwar, Bachtiar, \& Hamid, 2009). Crisis management strategies such as restrain and seclusion are the last option if all the ways are unsuccessful. However, it should be conducted according to the standard and procedure, and it even requires 
debriefing or expressing feeling sessions after the restrain involving both the clients and the health workers, given that restrain and seclusion are traumatic experiences (Goulet \& Larue, 2016). In the case of this research, the clients were to be given interventions that focused on preventive and anticipatory strategies through treatment as usual (TAU), acceptance and commitment therapy (ACT), and family psychoeducation (FPE).

One of the anticipatory strategies for the management of aggressive behavior is psychotherapy such as acceptance and commitment therapy (ACT). ACT is a thirdwave behavioral therapy with the purpose of not changing the clients' unpleasant experience but to get them to respond to the stressors in order to live with the problem peacefully and of fostering positive behaviors for them to achieve their goals (Hayes, 2004). ACT in previous literature was shown to have significantly reduced signs of aggressive behavior (53.49\%) (Sulistiowati, Keliat, \& Wardani, 2014) and effectively decreased rehospitalization after a 4-month to 1-year follow-up (Bach, Hayes, \& Gallops, 2012).

The environmental modification that involves the family is also important since the family plays a crucial role in the client's care management (Susanti, Lovell, \& Mairs, 2018). This statement is true as the burden felt by families living with clients with schizophrenia is significantly high and affecting the families' quality of life (Stanley, Balakrishnan, \& Ilangovan, 2016). Family psychoeducation (FPE) is one of the nursing interventions for the family to improve the family's ability to provide appropriate care for the client (Caqueo-Urízar, Rus-Calafell, Urzúa, Escudero, \& Gutiérrez-Maldonado, 2015). FPE has been proven to be effective in improving the prognosis and social functioning and in reducing the recurrence rate of children with psychosis (Gearing, 2008). FPE was also effective in reducing symptoms of aggressive behavior in clients with schizophrenia by increasing the clients' ability to control anger and improving the families' ability to care for the family members with aggressive behavior (Setiawan, 2017).

Nursing treatment as usual (TAU) has been conducted widely by psychiatric nurses on clients with schizophrenia in Indonesia, but psychotherapies are still rarely known and applied by nurses in the country. Several studies showed a better outcome when TAU combined with psychotherapies (Bach, Gaudiano, Hayes, \& Herbert, 2013; Ghouchani et al., 2018). Previous studies already showed the effectiveness of acceptance and commitment therapy in schizophrenia, but there was no study published in case series about administering ACT and FPE together in Indonesia, specifically on clients with schizophrenia and aggressive behavior. This case series study showed a nursing process that combines ACT and FPE with TAU as a feasible and effective treatment option for nurses in treating aggressive behavior in psychosis.

\section{OBJECTIVE}

This case series study aimed to investigate the effectiveness of acceptance and commitment therapy (ACT) and family psychoeducation (FPE) combined with treatment as usual (TAU) on clients with schizophrenia and aggressive behavior. 


\section{METHODS}

\section{Design and participants}

This study was conducted using a case series as an observational descriptive research design. The case series was selected to present several cases with the same characteristics, same intervention, and specific selection criteria. Four cases of clients with aggressive behavior were selected to be reported in this article according to some certain criteria such as clients having paranoid schizophrenia, having a history of aggressive behavior, having an unpleasant experience related to aggressive behavior, having a relapse history, having received TAU and ACT, and having families receiving FPE.

\section{Ethical consideration}

Each client has provided written informed consent to ensure that he/she joined the therapy voluntarily and met the ethical criteria. This study has received permission from Marzuki Mahdi Hospital for reporting.

\section{Interventions}

The interventions were carried out by providing nursing treatment as usual (TAU) and ACT for the clients and FPE for the families. TAU was conducted in collaboration between the researchers and the ward nurses 7 times and evaluated at each meeting. TAU consisted of 1) physical intervention such as deep breathing exercise and anger release methods like hitting soft objects, 2) medication management, 3) social intervention such as feeling expression and asking and rejecting exercise, and the last, 4) spiritual intervention.

Acceptance and commitment therapy was applied 7 times as well by the researchers in 4 sessions for an average of 30-45 minutes each session. The sessions consisted of 1) discussing unpleasant events or experiences, 2) discussing responses related to unpleasant experiences, 3) identifying impacts of responses and acceptance exercise, and 4) identifying the value of the clients and discussing how to commit to the therapy and to achieve the clients' goals based on their value. The intervention was not only given to the clients but also for the families.

FPE was administered by the researchers to the families for them to provide support for the clients during visits to the hospital or when in contact with family members at the hospital by telephone. The researchers called the family to ask for approval and invited them to the hospital to join the research. FPE was conducted on the families 2-3 times in 6 sessions for 45-60 minutes each session. FPE sessions consisted of 1) identifying clients' health problems and educating the families to care for the health problems, 2) educating the families about other health problems, 3) family stress management, 4) family burden management, 5) utilizing the support system, and 6) evaluating the benefits of family psychoeducation. The whole interventions were conducted for 6 weeks using the stress adaptation model by Stuart.

\section{Evaluation}

The evaluation process carried out by assessing the symptoms and abilities of the clients. The symptoms assessment used a tool assessment instrument that developed 
based on the Stuart model with a total number of symptom items of 47, consisting of 12 cognitive symptom items, 12 affective symptom items, 9 physiological symptom items, 9 behavioral symptom items, and 5 social symptom items. The score ranged from 0 to 47; the higher the score, the worse the symptoms, and vice versa.

The clients' ability assessment for TAU consisted of 4 items, namely, 1) the ability to do deep breathing relaxation, 2) the ability to understand the right drug administration, 3 ) the ability to express feelings when angry and know how to reject and ask for help in a good way, and 4) the ability to do spiritual activities to control anger. Meanwhile, the ability assessment for ACT consisted of 3 items, namely, 1) the ability to express unpleasant events and identify the values in them, 2) the ability to accept illness and unpleasant experiences, and 3) the ability to commit to preventing recurrence. There are 7 ability items in total, and the score ranged from 0 to 7 ; the higher the score, the better the ability. The evaluation performed by assessing the alteration of the symptoms score and the clients' ability for each meeting.

\section{RESULTS}

\section{Characteristics of clients}

All participants were clients with schizophrenia who were treated in the adult ward. The specific history of each client is shown in Table 1.

\section{Table 1. Client's history}

\begin{tabular}{|c|c|c|}
\hline No & Name (Age) & History \\
\hline 1 & $\begin{array}{l}\text { Mr. W } \\
\text { (25) }\end{array}$ & $\begin{array}{l}\text { Has a mental illness since } 2013 \text {, admitted to the hospital for the 3rd time } \\
\text { due to aggressive behavior, and had a command hallucination to harm } \\
\text { others. Withdrawal from antipsychotic drugs over the last few months } \\
\text { had been stocked for two weeks, felt pressured by his brother. } \\
\text { Antipsychotic drugs included Depakote } 2 \times 2 \mathrm{mg} \text {, Onzapine } 1 \times 15 \mathrm{mg} \text {, } \\
\text { and Trihexyphenidyl } 2 \times 2 \mathrm{mg} \text {. }\end{array}$ \\
\hline 2 & $\begin{array}{l}\text { Mr. S } \\
(31)\end{array}$ & $\begin{array}{l}\text { Has a mental illness since 2014, admitted to the hospital for the 3rd time } \\
\text { because of aggressive behavior toward friends. Discontinuous } \\
\text { antipsychotic drugs for the last } 6 \text { months, an unpleasant experience due } \\
\text { to humiliation by friends and parents. Antipsychotic drugs included } \\
\text { Haloperidol } 3 \times 5 \mathrm{mg} \text {, THP } 3 \times 2 \mathrm{mg} \text {, Risperidone } 2 \times 2 \mathrm{mg} \text {, Clozapine } \\
1 \times 25 \mathrm{mg} \text {. }\end{array}$ \\
\hline 3 & Mr. Wi (22) & $\begin{array}{l}\text { Has a mental illness since } 2013 \text {, admitted to the hospital for the } 3 \text { rd time } \\
\text { due to aggressive behavior, consumed excessive cigarettes, and } \\
\text { antipsychotic drugs. Had experiences related to parental divorce and has } \\
\text { been pressured by his mother. Antipsychotic drugs included were } \\
\text { Haloperidol } 3 \times 5 \mathrm{mg} \text {, THP } 3 \times 2 \mathrm{mg} \text {, Risperidone } 2 \times 2 \mathrm{mg} \text {, Clozapine } 1 \times 25 \\
\text { mg. }\end{array}$ \\
\hline 4 & $\begin{array}{l}\text { Mr. D } \\
\text { (27) }\end{array}$ & $\begin{array}{l}\text { Has a mental illness since } 2009 \text {, admitted to the hospital for the } 2 \text { nd time } \\
\text { because of attacking his neighbors. Had a history of irregular } \\
\text { antipsychotic medication, consumed tramadol, and marijuana. } \\
\text { Unpleasant experiences were the death of his grandmother and bullied } \\
\text { by his schoolmates. Antipsychotic drugs including Haloperidol } 3 \times 5 \mathrm{mg} \text {, } \\
\text { THP } 3 \times 2 \mathrm{mg} \text {, Risperidone } 2 \times 2 \mathrm{mg} \text {, Clozapine } 1 \times 25 \mathrm{mg} \text {. }\end{array}$ \\
\hline
\end{tabular}




\section{Symptoms and clients' ability after TAU, ACT, and FPE}

The alteration of the symptoms number and clients' ability number during the seven meetings are explained in Table 1.

Table 2. Symptoms and clients' ability alteration at each meeting

\begin{tabular}{ccccccccc}
\hline \multirow{2}{*}{ Meeting } & \multicolumn{4}{c}{ Symptoms } & \multicolumn{4}{c}{ Client's Ability } \\
\cline { 2 - 10 } & Mr. W & Mr. S & Mr. Wi & Mr. D & Mr. W & Mr. S & Mr. Wi & Mr. D \\
\hline M1 & 9 & 12 & 9 & 13 & 1 & 1 & 2 & 2 \\
\hline M2 & 9 & 11 & 9 & 12 & 3 & 2 & 3 & 3 \\
\hline M3 & 7 & 9 & 7 & 10 & 4 & 4 & 4 & 4 \\
\hline M4 & 6 & 6 & 4 & 7 & 4 & 4 & 5 & 4 \\
\hline M5 & 4 & 6 & 2 & 7 & 5 & 4 & 5 & 4 \\
\hline M6 & 1 & 3 & 2 & 5 & 6 & 6 & 6 & 6 \\
\hline M7 & 1 & 2 & 0 & 4 & 7 & 7 & 7 & 7 \\
\hline M=Meeting & & & & & & & &
\end{tabular}

Table 2 shows the results of the symptoms evaluation and the clients' ability from the first day to the seventh day after TAU, ACT, and FPE. In general, the table explains that the clients experienced decreased numbers of symptoms and increased ability after interventions. In all clients, the frequency of meetings was more in social ways and drug adherence intervention. In ACT intervention, most clients experienced repetition two to three times in session 3, while in FPE intervention, the second session repeated more often. In Client 1, there was a consistent decline in symptoms at each meeting. However, there was still one cognitive symptom left at the end of the intervention. The client still revealed that he was unable to communicate and express his feelings well. In Client 2, an increase in ability and decrease in symptoms also obtained after the combination of intervention, but there were still two residual symptoms left. They were cognitive symptoms (blaming) and social symptoms (feeling rejected).

In Client 3, there were no more behavioral and physiological symptoms found in the initial assessment. The most symptom reduction was obtained at meeting 4 after giving FPE to the family. At the last meeting, there were no signs of risk of aggressive behavior found in Client 3. This might be caused by the contribution of the family along with the nurses to meeting patient needs and healthcare outcomes. In Client 4 , there were more symptoms of aggressive behavior left at the last meeting compared to the other clients. The symptoms included blaming, irritability, instability, and feeling rejected by the people around him. We also found that Client 4 had a history of drug abuse, which could be a factor that contributed to the worsening of the symptoms of mental illness.

\section{DISCUSSION}

The results of this study revealed that all clients showed a significant decrease in aggressive behavior symptoms and an increase in the ability to control anger after TAU and ACT. The better the ability of the client, the lesser the symptoms show, as seen in 
Table 2. The effectiveness of TAU already discussed in the previous research. Clients with aggressive behavior showed an improvement in the ability to control anger independently through the physical intervention, medication compliance, social way, and spiritual way as well as a reduction of length of stay at the hospital (Keliat, Azwar, Bachtiar, \& Hamid, 2009). TAU delivered along with acceptance and commitment therapy. The results showed that ACT also reduced the symptoms of aggressive behavior and increased the clients' commitment to the therapy. Commitment capability proved by the adherence of the clients to the therapy program and the medication. This result is in line with that of a previous study, which stated that medication adherence of the clients had increased both after the provision of education and ACT (52.7\%) and after the provision of only ACT (36.85\%). A combination of ACT and TAU also reported being more effective in decreasing aggressive behavior and in improving the general health of the clients with psychosis than a sole TAU (Ghouchani et al., 2018). ACT was also significantly effective in improving the positive symptoms of schizophrenia (Shawyer et al., 2016), reducing the rate of relapse, and reducing the cost of care for clients with psychosis (Butler et al., 2016).

Unpleasant experiences were found in all clients as factors of aggressive behavior, and most of the clients reported family conflicts as one of such factors. However, problems with the environment, including with friends, could also trigger aggressive behavior in the clients. A previous study confirmed that the aggressive behavior committed by clients with schizophrenia was a response to the sense of loss, or rights deprivation by others, followed by feelings of frustration, fear, unfairness, and anger, which caused them to conclude that others were responsible for their problems (Rueve \& Welton, 2008). Unpleasant experiences or feeling humiliated could influence the content of the hallucinations experienced by clients with schizophrenia (Hayward, Strauss, \& McCarthy-Jones, 2014). In this case, one client experienced command hallucinations to injure others. Clients who experienced hallucinations to injure themselves and others felt like the voice makes them very powerful and obliged to follow the command (Shawyer, Mackinnon, Farhall, Trauer, \& Copolov, 2003; Bucci et al., 2013).

The results stated that there were still residual symptoms left in cognitive and social aspects, such as blaming and feeling rejected. The reasons why residual symptoms persisted in several clients might be related to the duration of ACT intervention. A previous study revealed that ACT effectively decreased the symptoms of psychosis in clients with traumatic experiences such as sexual abuse and schizophrenia and increased their acceptance of the disease as well, albeit over a longer duration (12 sessions) (Jansen \& Morris, 2017). Another factor that caused the higher number of residual symptoms in Client 4 might be due to the client's substance abuse history that might be worsening the symptoms of schizophrenia (Green, Noordsy, Brunette, \& O'Keefe, 2008).

Conflict in the family, as expressed by Clients 1, 2, and 3 was critical because family is the main support system for the clients. The bad relationship between the clients and the families was often due to the high burden of care. Families who were living with the schizophrenic clients revealed burdens (Rafiyah, 2011; Susanti, Lovell, \& Mairs, 2019), both objective burden such as time and cost of care $(85.3 \%)$ and subjective burdens 
such as feelings of shame, worry, and disruption to personal time $(84.2 \%)$ (Lasebikan \& Ayinde, 2013). The high burden of caring for a family member with schizophrenia then attributed to a high expressed emotion (EE) in the family. EE defined as a behavior or emotion such as criticism, anger, or blame, or an inclination to show rejection to people with mental illness (Amaresha \& Venkatasubramanian, 2012; Nirmala, Vranda, \& Reddy, 2011). High EE in the family causes people with schizophrenia to feel unaccepted and unsupported and causes their risk of relapse to increase (Bogojevic, Ziravac, \& Zigmund, 2015).

Family psychoeducation (FPE) was delivered to the families to improve their ability to perform the five family health tasks as the families expected to be the main support system for the clients. The important roles of the family can be seen from the results showing all clients experienced significant symptoms of relief following FPE therapy. As Client 4 had no family conflict history, the feeling of being taken cared for by and getting support from the family seemed to be a great cause of the client's symptoms improvement. The effectiveness of FPE was also shown in a previous study, which stated that FPE was effective in reducing the severity of schizophrenia symptoms in the clients not only shortly after the intervention but also 1 month after (Sharif, Shaygan, \& Mani, 2012). Another study has also shown that FPE increased the family's active participation in client care management as well as enhanced the client's compliance with medication, prevented relapse, and improved social functioning (Ran, Chan, Guo, \& Xiang, 2015).

This study described the whole process of nursing care for clients with schizophrenia and aggressive behavior, but it also had some limitations that should be addressed. The limitations to consider are that this study had no control group and that it had no analysis of client medication which allowed the researchers to compare and ensure the effectiveness of the therapies.

\section{CONCLUSION}

This study stated that nursing intervention as usual and acceptance and commitment therapy combined with family psychoeducation could be a better choice to help clients reduce the symptoms of aggressive behavior and improve their ability to control anger. This study recommends combining the nursing intervention as usual with another psychotherapy in a clinical setting and to strengthen family involvement in clients' treatment through family psychoeducation to get a better outcome, especially in clients with aggressive behavior. Furthermore, ongoing follow-up research is necessary to measure how well clients are committed to their therapy.

\section{ACKNOWLEDGEMENT}

The researchers would like to thank all participants in this study.

\section{CONFLICT OF INTEREST}

None 


\section{REFERENCES}

Amaresha, A. C., \& Venkatasubramanian, G. (2012). Expressed emotion in schizophrenia: an overview. Indian Journal of Psychological Medicine, 4(1), 12-20. doi:10.4103/0253-7176.96149.

Bach P., Gaudiano B. A., Hayes S. C., Herbert J. D. (2013). Reduced believability of positive symptoms mediates improved hospitalization outcomes of Acceptance and Commitment Therapy for psychosis. Psychosocial Psychological Social Integration Approaches, 5, 166-174.

Bach, P., Hasyes, S. C., \& Gallop, R. (2012). Long-term effects of brief acceptance and commitment therapy for psychosis. Behaviour Modification, 36(2), 165-581. doi:10.1177/0145445511427193.

Bogojevic, G., Ziravac, L., \& Zigmund, D. (2015). Impact of expressed emotion on the course of schizophrenia. European Psychiatry, 30(1), 390. doi:10.1016/S09249338(15)30309-6.

Buanasari, A., Daulima, N. H. C., \& Wardani, I. Y. The experience of adolescents having mentally ill parents with pasung. Enfermeria Clinica, 28(1), 83-87. doi:10.1016/S1130-8621(18)30043-3.

Bucci, S., Birchwood, M., Twist, L., Tarrier, N., Emsley, R., \& Haddock, G. (2013). Predicting compliance with command hallucinations: anger, impulsivity and appraisals of voices' power and intent. Schizophrenia Research, 147(1), 163-168. doi:10.1016/j.schres.2013.02.037.

Butler, L., Johns, L. C., Byrne, M., Joseph, C., O’Donoghue, E., Jolley, S., ... \& Oliver, J. E. (2016). Running acceptance and commitment therapy groups for psychosis in community settings. Journal of Contextual Behavioral Science, 5(1), 33-38. doi:10.1016/j.jcbs.2015.12.001.

Caqueo-Urízar, A., Rus-Calafell, M., Urzúa, A., Escudero, J., \& Gutiérrez-Maldonado, J. (2015). The role of family therapy in the management of schizophrenia: challenges and solutions. Neuropsychiatric disease and treatment, 11, 145-151. doi:10.2147/NDT.S51331.

Fleischman, A., Werbeloff, N., Yoffe, R., Davidson, M., \& Weiser, M. (2014). Schizophrenia and violent crime: a population-based study. Psychological Medicine, 44(14), 3051-3057. doi:10.1017/S0033291714000695.

Gearing, R. E. (2008). Evidence-based family psychoeducational interventions for children and adolescents with psychotic disorders. Journal of the Canadian Academy of Child and Adolescent Psychiatry, 17(1), 2-11.

Ghouchani, S., Molavi, N., Massah, O., Sadeghi, M., Mousavi, S. H., Noroozi, M., ... Farhoudian, A. (2018). Effectiveness of Acceptance and Commitment Therapy (ACT) on aggression of patients with psychosis due to methamphetamine use: A pilot study. Journal of Substance Use, 23(4), 402-407. doi:10.1080/14659891.2018.1436602.

Goulet, M., \& Larue, C. (2016). Post-seclusion and/or restraint review in psychiatry: A scoping review. Archives of Psychiatric Nursing, 30(1), 120-128. doi:10.1016/j.apnu.2015.09.001.

Green, A. I., Noordsy, D. L., Brunette, M. F., \& O'Keefe, C. (2008). Substance abuse and schizophrenia: Pharmacotherapeutic intervention. Journal of Substance Abuse Treamentt, 34(1). 61-67. doi:10.1016/j.jsat.2007.01.008. 
Haddock, G., Eisner, E., Davies, G., Coupe, N., \& Barrowclough, C. (2013). Psychotic symptoms, self-harm and violence in individuals with schizophrenia and substance misuse problem. Schizophrenia Research, 151(1-3), 215-220, doi:10.1016/j.schres.2013.10.031

Hayes, S. C. (2004). Acceptance and commitment therapy, relational frame theory, and the third wave of behavioral and cognitive therapies. Behaviour Therapy, 35(4), 639-665. doi:10.1016/S0005-7894(04)80013-3

Hayward, M., Strauss, C., \& McCarthy-Jones, S. (2014). Psychological Approaches to Understanding and Treating Auditory Hallucinations: From Theory to Therapy (Explorations in Mental Health). New York: Taylor and Francis Group.

Jansen, J. E., \& Morris, E. M. J. (2017). Acceptance and commitment therapy for posttraumatic stress disorder in early psychosis: A case series. Cognitive and Behavioral Practice, 24(2), 187-199. doi:10.1016/j.cbpra.2016.04.003

Keliat, B. A., Azwar, A., Bachtiar, A., \& Hamid, A. Y. S. (2009). Influence of the abilities in controlling violence behaviour to the length of stay of schizophrenic clients in Bogor mental hospital, Indonesia. Medical Journal Indonesia, 18(1), 3135. doi:10.13181/mji.v18i1.336.

Knezevic, V., Mitrovic, D., Drezgic-Vukic, S., Knezevic, J., Ivezic, A., SiladjiMladenovic, D., \& Golubovic, B. (2016). Prevalence and correlates of aggression and hostility in hospitalized schizophrenic patients. Journal of Interpersonal Violence, 32(2), 151-163. doi:10.1177/0886260515585537

Lasebikan, V., \& Ayinde, O. (2013). Family burden in caregivers of schizophrenia patients: Prevalence and socio-demographic correlates. Indian Journal of Psychological Medicine, 35(1), 60-66. doi:10.4103/0253-7176.112205

Nirmala, B. P., Vranda, M. N., \& Reddy, S. (2011). Indian Journal of Psychological Medicine, 33(2), 119-122. doi:10.4103/0253-7176.92052

Rafiyah, I. (2011). Review: Burden on Family Caregivers Caring for Patients with Schizophrenia and Its Related Factors. Nurse Media Journal of Nursing, 1(1), 2941. doi:10.14710/nmjn.v1i1.745

Ran, M. S., Chan, C. L., Ng, S. M., Guo, L. T., \& Xiang, M. Z. (2015). The effectiveness of psychoeducational family intervention for patients with schizophrenia in a 14-year follow-up study in a Chinese rural area. Psychological Medicine, 45(10), 2197-2204. doi:10.1017/S0033291715000197.

Richmond, J. S., Berlin, J. S., Fishkind, A. B., Holloman, G. H., Zeller, S. L, Wilson, M. P., .. \& Ng, A. T. (2012). Verbal de-escalation of the agitated patient: Consensus statement of the American Association for Emergency Psychiatry project BETA de-escalation workgroup. Western Journal of Emergency Medicine, 13(1),17-25. doi:10.5811/westjem.2011.9.6864.

Rueve, M. E., \& Welton, R. S. (2008). Violence and mental illness. Psychiatry (Edgmont), 5(5), 34-48.

Setiawan, H. (2017). Penerapan terapi kognitif perilaku dan terapi asertif terhadap klien risiko perilaku kekerasan di ruang akut rumah sakit jiwa [Application of CBT and Assertive training to clients with risks of aggressive behaviors in acute psychiatric care] (Unpublished thesis). Universitas Indonesia, Depok, Indonesia. 
Sharif, F., Shaygan, M., \& Mani, A. (2012). Effect of a psycho-educational intervention for family members on caregiver burdens and psychiatric symptoms in patients with schizophrenia in Shiraz, Iran. BMC Psychiatry, 12(48), 1-9. doi:10.1186/1471244X-12-48.

Shawyer, F., Farhall, J., Thomas, N., Hayes, S. C., Gallop, R., Copolov, D., \& Castle, D. J. (2016). Acceptance and commitment therapy for psychosis: randomised controlled trial. The British Journal of Psychiatry, 210(2), 140-148. doi:10.1192/bjp.bp.116.182865.

Shawyer, F., Mackinnon, A., Farhall, J., Taruer, T., \& Copolov, D. (2003). Command hallucinations and violence: Implications for detention and treatment. Psychiatry, Psychology and Law, 10(1), 97-107. doi:10.1375/pplt.2003.10.1.97.

Stanley, B., Molcho, A., Stanley, M., Winchel, R., Gameroff, M. J., Parsons, B., \& Mann. J. J. (2000). Association of aggressive behavior with altered serotonergic function in patients who are not suicidal. American Journal of Psychiatry, 157(4), 609-614. doi:10.1176/appi.ajp.157.4.609.

Stanley, S., Balakrishnan, \& Ilangovan, S. (2016). Psychological distress, perceived burden and quality of life in caregivers of persons with schizophrenia. Journal of Mental Health, 26(2), 134-141. doi:10.1080/09638237.2016.1276537.

Stuart, G. W. (2013). Principles and Practice of Psychiatric Nursing. Missouri: Elsevier Mosby.

Sulistiowati, N. M. D., Keliat, B. A., \& Wardani, I. Y. (2014). Pengaruh acceptance and commitment therapy terhadap gejala dan kemampuan klien dengan resiko perilaku kekerasan [The effect of Acceptance Commitment Therapy on symptoms and Ability on Clients with aggressive behaviour]. Jurnal Keperawatan Jiwa, 2(1), 5157.

Susanti, H., Lovell, K., \& Mairs, H. (2018). What does the literature suggest about what carers need from mental health services for their own wellbeing? A Systematic Review. Enfermeria Clinica, 28(1), 102-111. doi:10.1016/S1130-8621(18)30047-0

Susanti, H., Lovell, K., \& Mairs, H. (2019). Emotional reactions and coping strategies of carers of people with serious mental illnesses: A focus group study. Enfermeria Clinica, 29(2), 275-27. doi:10.1016/j.enfcli.2019.04.033.

Torrey, E. F. (2011). Stigma and Violence: Isn't It Time to Connect the Dots?. Schizophrenia Bulletin, 37(5), 892-896. doi:10.1093/schbul/sbr057.

Volavka, J. (2014). Aggression in psychoses. Advances in Psychiatry, 1-20. doi:10.1155/2014/196281.

Volavka, J., \& Citrome, L. (2011). Pathways to aggression in schizophrenia affect results of treatment. Schizophrenia Bulletin, 37(5), 921-929. doi:10.1093/schbul/sbr04. 